\title{
Luiz Nicolau Fagundes Varella
}

\author{
Vicente de Azevedo \\ Livre docente de Direito Judiciário Penal na Facul- \\ dade de Direito da Universidade de são Paulo.
}

\section{Primeiro professor de Processo civil e criminal. Primeiro Secretário da Academia de Direito de S. Paulo}

Repetiu o poeta o nome do avô paterno, Luiz Nicolau Fagundes Varella.

Escassos os informes a respeito do homônimo. De sua vida, livros e arquivos pouco revelam. Justificado esquecimento?

Colou grau de doutor em direito na Universidade de Coimbra. Oriundo da Província do Rio de Janeiro, o ter sido enviado a ler códigos e leis na douta Coimbra, é índice de que provinha de gente de prol.

Munido do sézamo que lhe abria tôdas as possibilidades para a vida pública, retornou aos seus lares e exercia o ministério público da advocacia na metrópole do Reino do Brasil, quando D. João VI abalou para Portugal.

Não tardou se cuidasse de eleger os representantes do Brasil perante as Côrtes gerais que deveriam discutir a Constituição e dar a Portugal o novo regime político. Entre os indigitados para deputados, figurava o advogado na Província do Rio de Janeiro. Nele depositavam os eleitores vivas esperanças de que pugnaria por seus direitos e seria o amparo de seus ideais. Eleito, satisfez as aspirações do eleitorado? Correspondeu ao que dêle se esperava? Não, responderá a notícia dêste periodo da história do Brasil, que tão de perto diz com a de Portugal, a ponto de com ela se confundir. Poderão apreciá-lo os 
leitores das páginas documentadas de Gomes de Carvalho, M.E. Os deputados brasileiros nas Côrtes gerais de 1821". (Porto, liv. Chardron, 1912).

S. Paulo teve representação que exprimia o vigor da terra e de sua gente: Antônio Carlos, o orador máximo de seu tempo; Feijó, o grande Feijó, o engeitado da rua da Freira, que chegou a regente do Império; Vergueiro, portuguềs de nascimento, paulista de coração, uma das figuras políticas de maior complexidade; Fernandes Pinheiro, para só citar alguns, representação ilustre, que, no dizer de Tarquínio de Souza, nenhuma outra sobrepujava, e que resguardaria com denodo, o pundonor brasileiro. Altiva e corajosa, não conseguiria, entretanto, impedir o inevitável. No fragor dos debates, quando era vaiada nas ruas e no próprio recinto das Côrtes, quando, aos gritos e apupos se pretendeu abafar a voz potente de Antônio Carlos, foi que, impáviđo, desafiando a tempestade de impropérios, o santista ilustre bradou a apóstrofe que podia ter saido dos lábios de Mirabeau: "Do alto desta tribura, até os reis hão de me ouvir!" Fernandes Pinheiro declarou em sessão que não assinaria a Constituição prestes a votar-se, "por estar em manifesta contradição com a vontade de sua província." Apoiaram-no, na sessão seguinte, Antônio Carlos, Silva Bueno e Costa Aguiar. Em carta dirigida às Côrtes, num estilo que revelava bem o seu caráter, Feijó declarou que só juraria a Constituição "obrigado, violentado e arrastado."

Tímido por índole, não recebeu o advogado fluminense com ambas as mãos e com entusiasmo a idéia da deputação. Resistiu. Condescendeu.

Por circunstância fortuita, residentes, então, em Portugal eram quase todos os demais deputados pelo Rio de Janeiro: o bispo de Coimbra, D. Francisco de Lemos; o bispo d'Elvas, D. José J. da Costa de Azeredo Coutinho, o bacharel Luiz Martins Bastos; e como suplentes, ou substitutos: o médico Custódio Gonçalves Ledo e o bacha- 
rel em matemáticas Francisco Villela Barbosa, afastado êste, há perto de trinta anos, da pátria. O futuro primeiro marquês de Paranaguá deixara a marinha de guerra para dedicar-se ao magistério. Pertencia à Real Academia de Ciências de Lisboa, e foi, no parecer de Gomes de Carvalho, incontestàvelmente, o mais notável membro da representação fluminense; o único, talvez, que dignamente se portou.

Tomaram assento nas Côrtes de Lisboa, os representantes fluminenses no dia 10 de Setembro de 1821. Varella e Lemos Brandão acabavam de chegar do Rio de Janeiro pela charrua "Gentil americana."

A morte privou de improviso, logo no dia seguinte, a deputação da figura veneranda do insigne prelado Azeredo Coutinho. O outro bispo, mais que octogenário, limitou-se a receber o diploma. Não compareceu, nem prestou juramento. Só ao cabo de um mês é que reconheceu a impossibilidade de cumprir suas obrigações de representante do povo e desistiu do mandato. Para substituir o prelado falecido, foi convocado o primeiro suplente, Custódio Ledo, residente no Pôrto. $\mathrm{E}$ em lugar do antístite, venerando e inválido, na qualidade de suplente, Villela Barbosa.

Provinda da Revolução chamada Regeneradora, qual - ânimo das Côrtes de Lisboa em relação ao Brasil? Quais as suas disposições?

De princípio, apenas mal querença, a ciumeira mal contida, de haver Portugal vivido de 1808 a 1821 em situação de verdadeira inferioridade. Aqui, no Brasil, a sede do govêrno, a paz, o progresso. Lá a humilhação, a miséria e, administrativamente, a condição paradoxal de província do Brasil. Dêste estado de espírito nasceram os desígnios ocultos, e logo manifestos, de resduzir novamente o Brasil à condição de colônia, como se fôsse possível deter e fazer retroceder o curso da história... 
Um dos primeiros atos foi a determinação da retirada das fôrças militares. A seguir, a Comissão de Constituição, composta dos "regeneradores de primeira grandeza", Borges Carneiro, o grande jurisconsulto, Moura, um dos maiores oradores da assembléia, e Fernandes Thomaz propôs a supressão da Casa de Suplicação do Rio de Janeiro e a supressão de todos os demais tribunais criados por D. João VI. Martins Bastos, da deputação fluminense, não titubeou formular vivaz protesto. Acudiu em defesa da moção Fernandes Thomaz. Lançou mão do argumenta capcioso da extensão territorial do Brasil e da carência de comunicações. Onde quer se localizasse a Casa de Suplicação, ou instância suprema, haveria sempre descontentamento e queixumes. Aceito para argumentar o fundamento, muito peor era o remédio do que o suposto mal, de vez que os litigantes teriam de recorrer a Lisboa! Não se deteve o deputado que tão mal escondia seus intentos: descobrindo sentimentos que eram seus e que animavam a maioria, opinou francamente pelo restabelecimento da ađministração do novo reino nos moldes vigentes em 1808, até que se providenciasse nova organisação.

Principiava, assim, a obra da recolonisação do Brasil, a pretexto de manter e garantir a autoridade da pátria mãe sôbre o novo reino. Como, porém, a maior parte da representação do Brasil ainda não havia chegado a Lisboa, o bom senso, desta vez vencedor, permitiu o adiamento da discussão referente à supressão dos Tribunais. E quando, meses depois, voltou à ordem do dia, Varella alistou-se entre os que concordaram. Manifestou-se até a favor.

Um dos gracejos correntes na época, inventado talvez pelo "Correio brasiliense", era o de que o principe regente, apenas chegado ao Brasil, abrira por desfastio o Anuário de Lisbôa e copiara a lista das instituições da mãe pátria para reproduzir em sua nova capital, aquelas que aí existiam, sem cogitar das condições diferentes da terra, e sem corrigir os vícios do organismo adminisirativo de Portu- 
gal. Varella repete a facécia e dêste modo testemunha não alcançar a significação e as confluências da medida.

"Estas repartições criadas pelo almanac (disse) é justo que acabem pelo almanac. A extinção dêsses tribunais é muito precisa, é necessário acabar com estas sangue-sugas, que tanto têm arruinado a pátria." (Gomes de Carvalho, cit., pg. 161.)

Ao citado autor e a todos os leitores de hoje causa assombro a facilidade com que certos deputados ultramarinos concordavam com as medidas vexatórias e prejudiciais ao Estado que representavam. Mormente os representantes do Rio de Janeiro, a capital do país, que mais diretamente sofria. Para Gomes de Carvalho a explicação dessa atitude era: covardia e miopia intelectual. Diga-se logo, como adendo esclarecedor: a representação de S. Paulo não chegara ainda, e Villela Barbosa sòmente em Outubro tomou posse de sua cadeira.

A supressão dos Tribunais, que seria afinal aprovada, teve, no momento adiada sua discussão. Como discutir e resolver assuntos relativos à América, se a maioria dos deputados americanos ainda não participava da assembléia?

Voltaram, então os regeneradores as vistas para o príncipe regente, D. Pedro. E encareceram a necessidade de, fazendo-o voltar para a Europa, aprimorar a sua instrução e polir a sua educação. Convinha que viajasse, que frequentasse as Côrtes européias.. Não percebiam os deputados às Côrtes portuguêsas, que isto significava passar público atestado de ignorância e.. ausência de educação ao príncipe herdeiro das coroas de Portugal e do Brasil? Não contentes com decretar a volta do príncipe, timbravam em pisar e meter debaixo dos pés, o seu amor próprio. Atiravam-lhe setas certeiras, e por isso mesmo mais doridas. Falar em instrução e educação a respeito do príncipe, era aludir a corda em casa de enforcado. Com ou sem intenção, não importa, o fato é que meteram-no a ridículo. "Quando eu saí em agôsto do ano passado do 
Brasil (palavras de Fernandes Thomaz, que os Anais registram) o príncipe real entre a falta de outros conhecimentos, não sabia falar línguas: começava a falar francês com a princeza, mas era porque esta senhora não tinha tanta facilidade em falar outra língua e via-se o príncipe na necessidade de aprender."

Ora, se o príncipe não falava francês; se a princeza não tinha facilidade de exprimir-se noutra língua, - como se haviam entendido os jovens esposos? O que lhes valeu foi a linguagem do amor que é universal, não conhece idiomas, nem raças, e neste terreno D. Pedro I não se perdia: era senhor absoluto.

Extraordinário é que os parlamentares portuguêses não notassem que faziam o jôgo do Brasil: quanto mais destratassem o príncipe, mais depressa o levariam a abraçar a causa de nossa independência política.

No correr dos debates e no suceder das sessões, iam êles se capacitando de que a questão do Brasil se apresentava muito mais séria e oferecia aspectos muito mais graves. A antiga colônia atingira a maioridade política $\mathrm{e}$ anciava pela emancipação. A onda de independência que corria pela América era contagiante. Ainda assim demorava os constituintes a possuir aquela verdade que o atilado D. João VI manifestou quando, nas vésperas de partir declarou ao filho que ficava: "Pedro, se o Brasil se separar, seja ante para ti, que me has de respeitar, do que para algum dêsses aventureiros." (Oliveira Lima, D. Joâo VI no Brasil, tomo II, pg. 1125). Otávio Tarquínio de Souza, (A vida de D. Pedro I, tomo I) transcreve o texto da carta em que o então príncipe regente recorda ao pai as textuais palavras.

O novo sistema governativo imposto aos brasileiros importava sujeita-los decisivamente a Portugal, uma vez que todos os magistrados, os administradores da Fazenda, e os governadores de Armas ficavam na dependência direta de Portugal e das Côrtes. Cancelava-se dest'arte não só o decreto de 22 de Abril, em que D. João VI encarre- 
gara o príncipe real "do governo geral e inteira administração de todo o Reino do Brasil”, como se buscava apagar, no conjunto de seus atos e consequências, o que representara para a antiga colônia a transferência da sede da monarquia portuguêsa para o Rio de Janeiro. A bem dizer, negava-se a existência do Brasil, confundindo-o no simples conglomerado de províncias ultramarinas, significando, como todo, apenas uma expressão geográfica, e não mais uma entidade política, um povo, uma nação, um reino, em pé de igualdade com Portugal, assim proclamado na carta de lei de 16 de Dezembro de 1815, (Otávio Tarquínio de Souza, op. cit., tomo I, pgs. 314, 315.)

Uma das mais deliciosas ingenuidades das Côrtes constituintes consiste em ignorar o adjetivo patronímico brasileiro: eram os portuguêses habitantes do Brasil...

$\mathrm{E}$ quando os portuguêses acabaram por se convencer de que breve o Brasil romperia as amarras da sujeição e, contraproducentes haviam sido as medidas aprovadas pelas Côrtes, intolerável se tornou a permanência em Lisbôa. A retirada era o mais eloquente protesto. Sete representantes brasileiros, quatro paulistas e três baianos, fugiram seguindo para a Inglaterra, sem passaportes sem licença das Côrtes. Chamavam-se: Antônio Carlos, Silva Bueno, Diogo Feijó, Costa Aguiar, Cipriano Barata, Lino Coutinho e Francisco Agostinho Gomes. Dos que permaneceram em Lisbôa, recusaram-se a assinar a Constituição: Vergueiro, Muniz Tavares, José Joaquim de Faria, José Maria de Souza e Almeida. Assinaram-na os demais, e, entre êles Fernandes Pinheiro, que voltou atrás em seus propósitos, a instâncias de seu amigo o deputado português, Trigoso. Assinou-a, explicou suas memórias, "sacrificando-me, e acalmando a cólera que contra nós se exasperava."

Inùtilmente se exasperou a cólera contra os representantes brasileiros: assinada a 22 de setembro de 1822, dezoito dias antes havia a pátria nova recebido o batismo da 
independência, a sete de setembro, à margem do rio Ipiranga.

É manifesto que o tímido Varella não possuía a coragem impávida de um Andrada para afrontar o clima do recinto das sessões, das galerias, da arraia miúda. A carta que por aquêles dias escreveu a Antônio Carlos o príncipe D. Pedro, vale mais do que uma grã-cruz, mais do que um dos marquesados tão prodigalisados no primeiro império: "Meu amigo e do meu amigo Brasil. Constando-me que ao Congresso não foram 'apresentadas algumas das minhas cartas escritas a meu Pai, as quais lhe deviam fazer conhecer os meus sentimentos, amor do grande Brasil e zelo nacional, busco por êste meio, remetendo-lh'as tôdas para que me conheça e os meus pensares, e possa (se as não tiver ainda visto) pedi-las para que se façam públicas. Eu o conheço como o mais digno deputado americano; conheça-me a mim como o maior Brasileiro, e que pelo Brasil dará a última gota de sangue. Resta-me dizer-lhe que se lá não o apoiarem, em lugar de se cansar com debates, volte, que os Brasileiros o desejam cá para as suas Côrtes municipais. Tomo esta deliberação de me expressar assim porque conheço que é um verdadeiro Brasileiro, e de mais paulista, estimado de todos seguramente, e mui particularmente dêste seu amigo. Príncipe Regente."

O constituinte fluminense Luiz Nicolau Fagundes Varella, aterrado, encolhido na poltrona, passou a acompanhar a maioria, concedendo, por vêzes, mais do que ela pretendia, como em relação às causas pendentes de julgamento, na Casa de Suplicação. Colheu o prêmio de seu panurgismo: elegeram-no presidente das Côrtes. Efêmera glória, que servia para diminuir o prestígio de seus colegas de representação do Brasil.

Como repercutiu esta atitude no Rio de Janeiro? Tenha a palavra o cronista:

"Divulgados no Rio os debates, o povo indignou-se contra Varella, a tal ponto que o pobre homem, corrido e desorientado, não mais tomou a palavra nas Côrtes, con- 
tentando-se com seguir nas votações, os próceres da bancada americana. Parece que se procurava justificar com a falta de instruções." (Gromes de Carvalho, cit., pgs. $166,7)$.

Custa a crer que o deputado lançasse mão de justificativa tão desastrada. Que um diplomata obedeça a instruções de seu govêrno, compreende-se. Mas que um deputado concorde com medidas vexatórias e deprimentes alegando falta de instrução do eleitorado, é coisa que se não podia admitir.

A contrariedade do eleitorado fluminense extravasou, à moda do tempo, em panfletos e cartas abertas. Temos à vista a carta que - ao illustre deputado - em Côrtes o senhor - Luiz Nicolau Fagundes Varella - escreveo hum zelloso patriota - em 14 de Dezembro de 1821 dada ḋ luz - por - José Alves Ribeiro de Mendonça. Rio de Janeiro - na Imprensa Nacional. 1822."

$\mathrm{O}$ autor, que se oculta sob as iniciais J. T. e Ribeiro de Mendonça conclui a Introdução "confessando que estamos possuídos dos mesmos sentimentos da Carta que oferecemos ao público."

Assim principía o missivista: "Já antes que V. Excia. assumisse os votos desta Provincia para ser seu representante nessa Soberana Assembléa, eu tinha ouvido vagamente taxa-lo de egoista e de froxo; parece que não poucos motivos havião para dirigir a opinião publica a esse respeito, pois apezar da ardencia com que se pretendeo cohonestar a escolha dos imparciais Eleitores, e com que os Brasileiros amão a honrar e engrandecer em Publico os seus patricios, aquela opinião nunca foi destruida."

"Ah! e com que dôr não se tem feito aqui público que ... .. . V. Excia. illudindo as esperanças de encher-se de entusiasmo pelo amor da Patria, falha com o que podia coadjuvar para o uso dos Direitos e dos interesses destes Povos, que tinhão confiados de V. Excia. a guarda delles." 
T'eria Varella pretendido permanecer em Portugal e ali fixar residência? Afirma-o o autor da carta:

“Assáz notorio hé aqui que V. Excia. enchendo as suspeitas a que deo lugar a venda de todos os seos bens no seo Paiz, a disposição de não voltar mais a elle; tem-se dirigido como tinha premeditado, a, abandonando a causa da Patria, evadir-se a soffrer nella os males de que estava encarregado de deffendê-la; que lastima! e pode encontrar-se em um Brasileiro essa immoral resolução "

As exprobações se derramam pelas doze paginas da carta, que assim termina:

"Essas reflexoens, que são adquiridas no uso da communicação de um grande numero de individuos, são filhas do entusiasmo que vejo em todos os Brasileiros; ellas apparecerão ahí reprodusidas conforme a linguagem de cada um dos que se propozérem a fazê-las publicas; e eu espero do Patriotismo de V. Excia. que as fará vêr aos outros Senhores Deputados, visto que he desnecessario dirigir-me a cada hum em particular, e que a emolação os fará cooperar com os illustres Deputados de S. Paulo a bem da causa publica do Brasil; e cujas instruções junto envio a V. Excia. que me permitirá assinar-me,

Rio de Janeiro, 14 de dezembro de 1821. De V. Excia. Patricio

$$
\text { af eiçoado, }
$$

$$
\text { J. T." }
$$

Desde então o nome do deputado fluminense não mais apareceu no cenário político do país: não participou da Constituinte nacional, nem na Assembléia geral que se the seguiu. Mergulhou no silêncio e na mediocridade. Proclamada a independência, viu o País organisar-se politicamente, e galgarem posições justamente os componentes daquela elite que o representara nas Côrtes: Feijó e Araujo Lima, regentes do Império; Antônio Carlos, Villela Barbosa, Vergueiro, Lino Coutinho e outros, ministros de Estado; e quase todos tiveram assento no Senado do Im- 
pério, que é um dos nossos mais legítimos orgulhos do passado.

Fundados os Cursos jurídicos de S. Paulo e Olinda pela lei de 11 de agôsto de 1827, o primeiro a inaugurar-se foi o de S. Paulo, três meses depois, instalado "interinamente", como dizem os documentos da época, no Convento de S. Francisco. O primeiro diretor, possivelmente contemporâneo de Varella em Coimbra, doutor em leis, como êle, o tenente-general José Arouche de Toledo Rondon, a quem as neves dos setenta invernos não impediam desenvolvesse atividade no sentido de regularisar as aulas, solicitava ao Govêrno geral a nomeação dos professôres.

Ao velho Fagundes Varella ao ostracismo político acompanhou o insucesso na profissão. Comprova-o a nomeação a 22 de junho de 1828 para a cadeira de Processo, bem como para secretário na novel Academia. O preenchimento das cadeiras não obedecia ainda ao critério do concurso. Teria requerido o provimento o velho Varella? Certamente. Sabe-se que Bernardo Pereira de Vasconcellos o solicitou e não obteve, recebendo o requerimento o seguinte despacho do Imperador: "Escusado." É como hoje se dissesse: - "Aguarde oportunidade." Ou "Não há vaga." (Otávio Tarquínio de Souza, Bernardo Pereira de Vasconcellos e seu tempo, Rio, 1937, pgs. 57 e segs.) O curioso é que o candidato, desembargador em disponibilidade no Maranhão, combatera no parlamento a localisação dos cursos jurídicos no interior do país. Queria-os no Rio de Janeiro.

Transcreve Almeida Nogueira do arquivo da Faculdade oficios do diretor Arouche Rendon a respeito dos dois lentes, Silva Lisbôa e Fagundes Varella. Formavam, aliás, êstes dois integrantes da primeira Congregação, uma perfeita parelha, empregado o termo no bom sentido.

Do Dr. Balthazar Lisbôa, lente de direito Eclesiástico, deixou testemunho um seu aluno, José Christiano Garção Stockler, mineiro de S. João del Rei, "Memórias estudantinas." Era um pobre velho doente, pusilânime, de uma 
covardia que causava dó. Tinha medo da própria sombra. Pele escura, de um tom carregado, tão carregado que chegava a ser eufemismo dizê-lo moreno; alto, magro, calvo, gago, usava óculos. Falava para dentro, em voz baixa, comendo as palavras. Uma cartola desbotada cobria-lhe a cabeça, quando andava pela rua. Queixando-se ao diretor da falta de respeito dos alunos, propoz que adotasse o uso da palmatória. Solteiro, morava no mosteiro de S. Bento. O Dr. Avelar Brotero, outro lente da época, e que substituiria Fagundes Varella na secretaria disse em aula, referindo-se ao colega Lisbôa: "O lente de direito Eclesiástico é um tratado completo de ignorância, covardia e bajulação." Praticou a imprudência de jogar as cristas com êste colega, Dr. Brotero. Ora, o lente de direito natural não era homem de meias tintas: desancou-o em tremendo descomponenda. Nem siquer empregou figura de metáfora, como o fêz muito mais tarde outro lente, não menos violento, porém mais espirituoso: "Nas razões do ex-adverso encontro o vestígio de mais pés do que possui a espécie humana.." Brotero chamou-o burro com tôdas as letras e o pobre homem recolheu o insulto sem um pio.

É de crer tenha obtido a cátedra por influência de seu irmão, o visconde de Cayrú, êste sim, vulto superior, cujo Direito mercantil foi, por muitos anos, o Código comercial, tal a sua autoridade. (Clovis Bevilaqua, Historia da Faculdade de direito de Recife, $1 .^{\circ}$ vol. pg. 18.)

O Dr. José Maria de Avelar Brotéro, português de nascimento, completava o trio dos primeiros professôres. Flagrante contraste fazia com os colegas. Assim registra o mesmo cronista mineiro:

"Brotero era moço, tinha família, sendo casado com uma senhora ilustrada, bonita, elegante; vestia-se bem; era alegre; reunia os amigos em sua casa para jantares; dava bailes todos os meses, com o comparecimento das famílias importantes da cidade tinha ótima biblioteca, era competente, fazia bons discursos, dava aulas com desembaraço, 
era altaneiro, corajoso, sincero nas suas manifestações; ultra-liberal, era quase ( $\mathrm{sic}$ ) ateu; enfrentava com coragem e altivez o bispo, o Presidente da Província, o diretor da Academia. Tratava os alnos com bondade e justiça, mas exigia dêles o mais rigido respeito, sendo estimado e respeitado. De estatura meã, compleixão forte, revelando saúde. De rosto corado, olhos azuis, cabelos loiros, penteados para trás, parecia um alemão. Era o melhor advogado de S. Paulo, e o mais procurado."

A Fagundes Varella, o professor, a idade trouxera todo um cortejo de achaques. Sofria da bexiga, tão ruim era sua letra, que o Diretor Arouche Rendon se viu obrigado a continuar a enviar manuscrita de seu próprio punho, tôda a correspondência oficial: "Chegou o Varella, e vi-me na necessidade de continuar no mesmo trabalho, por vêr que é um homem velho, doente e de muito má letra."

Ocorre indagar como se houve êste professor na regência da cadeira. Pela lei de 11 de agôsto de 1827, arts. $4 .^{\circ}$ e $5 .^{\circ}$, o ofício de secretário competia a um dos professôres substitutos, o qual, além do ordenado anual de. $800 \$ 000$ (oitocentos mil réis) percebia a gratificação mensal de $20 \$ 000$ (vinte mil réis). Uma vez que acumulava, sua nomeação foi para professor substituto. $\mathrm{E}$ mais: pelos Estatutos do visconde de Cachoeira, Luiz José de Carvalho e Mello, mandados observar enquanto as respectivas Congregações não organisassem outros, a cadeira de "processo civil e criminal, theorica e praticamente analysados", estava situado no quinto ano. Compêndio aconselhado: o tratado de Peniz. Ora, nomeado em 1828, o Dr. Varella faleceu em 1831. Conclusão melancólica: não exerceu as funções de secretário, porque sua letra era pior que a do septuagenário Diretor. Terá lecionado apenas a primeira turma de bacharéis formados em 1831. Explica-se: estudantes provindos de Coimbra, onde haviam iniciado o curso, concluiram-no aqui em S. Paulo assim se explica que, abertos os cursos em 1828, já em 1831 houvesse bacharéis. 
O entusiasmo do aluno contemporâneo pelo professor Avellar Brotero e os rasgados elogios que lhe faz, não podem passar sem um granum salis.

Para não ir mais longe: a congregação da Academia de direito de Recife não aprovou o compêndio de Direito natural de sua autoria, observando, muito discreta: "não lhe sendo todo presente, não podia fazer juizo certo sobre sua doutrina e sistema do autor"; as lições já estavam muito adiantadas; os estudantes iam se remediando com o Fortuna e finalmente, o Dr. João José de Moura trabalhava em fazer o seu compêndio. O parecer da comissão de instrução pública da Câmara dos Deputados, 1830, êsse, entretanto, não teve papas na língua: arrazou o Compêndio de direito natural. Ùltimamente o prof. Miguel Reale procurou, hàbil e piedosamente, rehabilitar a memória intelectual do Conselheiro Brotéro: Revista da Faculdade de direito, de S. Paulo, vol. 50 de 1955.

Quando o velho Fagundes Varella faleceu em 1831, seu filho Emiliano, que seria o pai do poeta, frequentava o Curso Anexo, o curral dos burros, ou dos bichos, como então era chamado, porque só veio a formar-se em 1836.

Casou-se duas vêzes e das esposas amadas à face de Deus e dos homens, deixou numerosa descendência. Também teve amores face a face e das sementes caídas à beira da estrada, houve um filho natural, com o qual andou às voltas o poeta, quando estudante em S. Paulo.

No campo da inteligência, o filho que mais se notabilisou foi o Dr. Carlos Arthur Busch Varella, bacharel em letras da primeira turma do Colégio de D. Pedro II, a 21 de Dezembro de 1843. Orador em nome dos jovens bacharéis, a escolha traçava o seu destino: depois de grangear fama de orador forense, coube-lhe a palavra nas festas jubilares do Colégio. (Vide Memoria histórica do Colegio de D. Pedro $I I .^{\circ}$, de autoria do mestre de historia pátria, Escragnolle Doria, pgs. 52 e 53.) 
Neste muñdo de enganos e ilusões, nada tão caprichoso como a glória. Não fôsse ela mulher! Celebridades póstumas, homens há que passam pela vida inteiramente desconhecidos. De outros, em número muito maior, se pode dizer que só contemporâneamente gosaram notoriedade e fama: do lustre das posições que ocuparam, do valor que se atribuiam, que lhes concediam os coevos, decorreu a efêmera notoriedade...

Com a morte apaga-se-lhes a memória. Nada mais do que foram é lembrado. Foram. Foram-se.

Da gama infinda destacamos uma variedade, quiçá a mais curiosa: a da celebridade retroativa, ou por fôrça de reflexo. E' o caso do velho Fagundes Varella. O neto não foi professor, nem doutor, nem mesmo bacharel. Não foi deputado, nenhuma posição política ocupou. Emprêgo algum exerceu, de nomeação ou eleição. Não possuíu sequer alguma dessas lantejoulas sociais tão cubiçadas e apreciadas, comendador ou barão. .

Entretanto... Quem imortalisou o nome: Luiz Nicolau Fagundes Varella?

Corriam os dias em que o autor do "Cântico do Calvário" não passava de "o poeta", o Varellinha, diminutivo repleto de desprêzo e de rancor, - quando pairava nas auras da fama certo homem de letras, orador consagrado no Rio de Janeiro.

O Teatro Lírico resplandecia num delírio de luzes. Conferência sôbre "A Caridade", dedicada ao Gabinete Portuguez de Leitura. Por mais extraordinário que pareça, o depoimento é absolutamente autêntico.

"O Sr. F - Minhas senhoras! Meus senhores! "Da caridade e da sua influência nas sociedades modernas". (Sorrindo e correndo os olhos sôbre a assistência.) " $\mathrm{E} o$ meu discurso está feito! E a caridade sois vós!" 
A imaginação completa fàcilmente o quadro: deliciado pela própria palavra, embriagado pela própria voz, o orador alisa os bigodes encerados, enquanto a assistência goza, embalada pelas frases redondas e bem cadenciadas.

Quê milagres faz a poesia! Quem hoje relembra o mimoso orador do Teatro Lírico?

Ao passo que o Varellinha, êsse, em letras de ouro tem seu nome inscrito por inteiro, no Panteon da Pátria. 